\title{
PATRIMÔNIO CULTURAL, IDENTIDADE E MEMÓRIA SOCIAL: Suas interfaces com a sociedade
}

\author{
Josemar Elias da Silva Junior \\ Mestrando em Ciência da Informação \\ Universidade Federal da Paraíba \\ josemar.elias90@gmail.com \\ Ana Lúcia Tavares de Oliveira \\ Mestranda em Ciência da Informação \\ Universidade Federal da Paraíba \\ ana7tavares@yahoo.com.br
}

\begin{abstract}
Resumo
Palavras-chave

Patrimônio Cultural. Identidade. Memória Social. Construção. Reconhecimento.
\end{abstract}

A memória é um elemento importante para compreendermos a construção e reconstrução das identidades dos grupos sociais. Entretanto, não podemos desconsiderar a relação do patrimônio cultural com identidade e memória social. Pretendemos evidenciar a memória social como uma questão necessária para as formações culturais e perpetuação destas, bem como compreendê-la enquanto um elemento de representação. Sendo assim, no discorrer deste texto desejamos tecer as semelhanças existentes entre: patrimônio cultural, identidade e memória social através de um levantamento bibliográfico sobre os termos, buscando fomentar a partir desta tríade, a importância do patrimônio para o contexto das construções identitárias.

\section{INTRODUÇÃO}

A história da humanidade é marcada por diversas transformações, seja na seara social, política ou tecnológica. A globalização é um exemplo obvio disto, ao aproximar as relações interpessoais, através dos seguintes acessos: transportes, tecnologias, meios de comunicação, especialmente, a partir da produção e disseminação de informação, por conseguinte do conhecimento, rompendo limites geográficos.

Tais acontecimentos interferirão e continua interferindo seja direta ou indiretamente nas relações culturais e de identidade, tornando a sociedade multicultural, pluricultural e constantemente diversificando sua dinâmica social.

Todavia é importante destacar que mesmo com essas modificações, determinados artefatos, tradições, culturas, dentre ou- tros elementos, se mantém "vivos" e resistentes a tais avanços no intuito de fundamentar uma construção social, bem como afirmar uma identidade cultural, que para Gonçalves (2005, p. 2):

Esses bens, por sua vez, nem sempre possuem atributos estritamente utilitários. Em muitos casos, servem evidentemente a propósitos práticos, mas possuem, ao mesmo tempo, significados mágicoreligiosos e sociais, constituindo-se em verdadeiras entidades, dotadas de espírito, personalidade, vontade, etc.

No entanto, não são objetos guardados de forma deliberada e sem sentido, mas comprova que tais elementos - tidos como bens - devem ser dotados de relevância social e política para que se justifique a sua pre- 
servação. Desta forma grupos sociais ou indivíduos em sua singularidade buscam através do colecionamento ou acumulação, revestidos de uma intencionalidade, preservar objetos e práticas que referem ou até mesmo justificam algum evento histórico ou identidade cultural, guardando em si, como já ponderado, relevância social. Segundo Gonçalves (2003, p. 22), "A categoria "colecionamento" traduz, de certo modo, o processo de formação de patrimônios", complementando este raciocínio Silveira e Lima Filho (2005, p. 40), alegam que na dimensão histórico-espacial que o objeto assume, este, por sua vez "[...] fala sempre de um lugar, seja ele qual for, porque está ligado à experiência dos sujeitos com e no mundo, posto que ele representa uma porção significativa da paisagem vivida".

Assim, a partir de um patrimônio cultural podemos compreender de fato $\mathrm{O}$ contexto cultural bem como a vivência de determinado grupo, estabelecendo uma conexão histórica. Neste panorama que versa em valores, identidades e preservação, tornase possível extrair o conceito de patrimônio cultural, que será na maioria das vezes atribuído a uma esfera coletiva, haja vista a relação que será tratada com memória e identidade coletiva. Corroborando com as considerações de Rodrigues (2012, p. 1, grifo nosso) afirma-se que "[...] esses conceitos são considerados como constructos sociais, sistemas de representação e de significação coletivamente construído, partilhado e reproduzido ao longo do tempo".

Esse trabalho discorrerá acerca das nuances que rondam os conceitos de patrimônio cultural, identidade e memória social enfocando a memória associada ao patrimônio como uma questão em certa medida imprescindível para a (re)construção e perpetuação identitária de um determinado grupo social.

\section{PATRIMÔNIO CULTURAL}

A partir da perspectiva de agrupamento/colecionamento de bens para a construção patrimonialística apresentada anteriormente, abarcando estes como detentores de uma relevância social, podemos adentrar no conceito trazido por Rodrigues (2012, p. 4) ao assegurar que patrimônio cultural:
É o conjunto de bens, materiais e imateriais, que são considerados de interesse coletivo, suficientemente relevantes para a perpetuação no tempo. O património faz recordar o passado; é uma manifestação, um testemunho, uma invocação, ou melhor, uma convocação do passado. Tem, portanto, a função de (re)memorar acontecimentos mais importantes; daí a relação com o conceito de memória social. [...] É o conjunto de símbolos sacralizados, no sentido religioso e ideológico, que um grupo, normalmente a elite, política, científica, económica e religiosa, decide preservar como patrimônio coletivo.

Nessa perspectiva o patrimônio não apenas nos faz recordar o passado, mas, prova sua relação intrínseca com a memória, sendo esta responsável pelo processo de reconstrução dos fatos e períodos passados. Outra questão pertinente para ser mencionada quando falamos na delimitação sobre a definição de patrimônio, são as várias perspectivas que um bem pode assumir frente a determinado grupo ou cultura.

Diante dessa concepção, o uso comum da palavra patrimônio, pode também configurar múltiplos elementos e eventos. De modo semelhante, “[...] multiplicação de pontos de vista sobre o papel do patrimônio na afirmação $e$ redefinição de identidades nacionais, regionais e locais", outrossim, "Frente a essa diversidade, a noção mesma de 'bem cultural' é problematizada por diversos autores" (DELGADO, 2005; PEIXOTO, 2005 apud SALAINI; GRAEFF, 2011, p. 172).

Complementando tal entendimento acerca da característica multifacetada que a palavra patrimônio pode assumir, Gonçalves (2005) assinala duas vertentes para tal 
explicação, que reverberam na forma como um grupo toma para si aquele bem patrimonial, afirmando que:

As variações de significado nas representações sobre a categoria 'patrimônio' oscilam possivelmente entre um patrimônio entendido como parte e extensão da experiência, e portanto do corpo, e um patrimônio entendido de modo objetificado, como coisa separada do corpo, como objetos a serem identificados, classificados, preservados, etc. (GONÇALVES, 2005, p. 8).

Opondo-se ao sentido da variabilidade, a Constituição Federal Brasileira de 1988, em seu art. 216, elenca os bens que podem ser compreendidos como patrimônio cultural brasileiro:

Art. 216. Constituem patrimônio cultural brasileiro os bens de natureza material e imaterial, tomados individualmente ou em conjunto, portadores de referência à identidade, à ação, à memória dos diferentes grupos formadores da sociedade brasileira, nos quais se incluem:

I - as formas de expressão;

II - os modos de criar, fazer e viver; III - as criações científicas, artísticas e tecnológicas;

IV - as obras, objetos, documentos, edificações e demais espaços destinados às manifestações artístico-culturais;

$\mathrm{V}$ - os conjuntos urbanos e sítios de valor histórico, paisagístico, artístico, arqueológico, paleontológico, ecológico e científico.

Ao analisar o patrimônio na perspectiva antropológica, sob viés etnográfico, buscando compreender a noção de cultura a partir da delimitação analítica do que se configuraria um patrimônio, vendo este como um "fato social total" compreensão trazida por Marcel Mauss (2003).
Gonçalves (2005, grifo nosso) nos coloca três categorias que devem ser analisadas, sejam elas: Ressonância (os objetos que compõem um patrimônio necessitam encontrar respaldo ou reconhecimento junto a seu grupo), Materialidade (assumida para quem o reconhece como tal, independentemente de sua condição tangível ou intangível) e Subjetividade (inexiste patrimônio o qual não é ao mesmo tempo condição e efeito de modalidades específica de autoconsciência individual ou coletiva).

Nesse aspecto vai se alargando nitidamente o envolvimento do patrimônio com as questões identitárias, que por sua vez está intrinsicamente relacionado com a identidade e consequentemente a memória social do grupo que considera um determinado patrimônio como um bem que lhe pertence.

Destarte, para definirmos os bens passíveis de serem considerados patrimônios e as nuances que envolvem sua delimitação, precisamos primeiramente compreendermos veementemente o que/quem definirá a sua preservação, principalmente, bem como de maneira inversa, melhor dizendo, para quem esta preservação será direcionada. Neste sentido, Azevedo Netto (2008, p. 8), induz que:
Os processos de preservação cultural e o arqueológico de modo mais contundente demandam uma série de questionamentos que implicam esclarecer quais patrimônios devem ser preservados, quem escolhe quais serão preservados e para quem é necessária essa preservação? E como todo questionamento complexo, tem a mesma complexidade como resposta.

Tendo ciência dos acordos sociais e das eventualidades que restaram pela construção e também a preservação de um patrimônio, torna-se pertinente observarmos criticamente as três categorias analíticas acima abordadas que viabilizam figurar o mesmo nesta categoria. 
Desta forma, é importante compreendermos a quem se destinará tal construção e preservação, uma vez que no processo de preservação, levar-se-á em consideração a ressonância social, assim como os interesses políticos que deseja estabelecer aquele(s) bem(bens) como patrimônio, pois, "É importante realçar esta ideia da manipulação ideológica do que pode ser ou não patrimônio; quem decide o que é relevante preservar é um determinado grupo (elite) e não o coletivo (povo) como um todo" (RODRIGUES, 2012, p. 4).

Tendo em vista isto, seguimos com as considerações de Azevedo Netto (2008, p. 9), expondo sua concepção sobre destinação:

[...] deve-se observar em primeiro lugar a realidade sociocultural em que o patrimônio está inserido, qual o processo histórico que configurou aquela comunidade, qual a relação desta comunidade com o seu território, em que há uma confluência das perspectivas entre as dimensões natural e cultural.

Nessa conjuntura, torna-se acentuadamente evidente que a definição de patrimônio e a sua construção é bastante complexa, porque, envolver uma série de características, fatores e atores neste processo. O que nos atenta a este caso é como as questões identitárias em uma perspectiva individual para coletiva são categóricas no sentido de reconhecimento daquele bem como pertencente a categoria de patrimônio, estabelecendo links com contextos passados, assim como interesses sociais e políticos que permeiam seu processo de preservação.

Nesse sentido, ao passo que fazemos esta inter-relação aos acontecimentos passados, precisamos da memória como ferramenta de legitimação das identidades sociais imbricadas. Desta forma, cabe a necessidade de se contextualizar identidade e memória, através de uma análise conceitual, com vistas a se evidenciar seus pontos de intersecção.

\section{IDENTIDADE}

Nos últimos anos, as discussões acerca das identidades assumiram lugar no campo das ciências sociais, principalmente a partir da década de 90. Com as transformações históricas ocorridas neste período houve a urgente necessidade de efetuar estudos sobre das identidades, como forma de se compreender melhor e dar explicação para as mudanças sociais ocasionadas por sociedades cada vez mais diversificadas, culturas híbridas e grupos complexamente heterogêneos.

Numa conceituação acerca do significado de identidade em um contexto de construção social, Castells afirma que identidade é "A fonte de significado e experiência de um povo. [...] Toda e qualquer identidade construída. A principal questão, na verdade, diz respeito a como, a partir de quê, por quem e para quê isso acontece" (CASTELLS, 2000, p. 22-23).

Sendo assim, o patrimônio estabelece com a identidade inúmeras relações, e por tal fato se torna difícil estabelecer conceitos pontuais para cada termo. Esta construção pode ser perpetrada de forma relacional. $\mathrm{Na}$ perspectiva de Rodrigues (2012, p. 03) "a construção da identidade, seja individual ou social, não é estável e unificada - é mutável, (re) inventada, transitória e, às vezes, provisória, subjetiva; a identidade é (re) negociada e vai-se transformando, (re) construindo-se ao longo do tempo", dialogando com a questão da multiculturalidade trazida em especial com a globalização, e, por conseguinte, as segmentações identitárias que surgem em face tal eventualidade.

$\begin{array}{cccc}\text { No que diz respeito às } & \text { fragmentações e reconstruções } & \text { de } \\ \text { identidades Hall assevera: } & & \end{array}$

A identidade torna-se uma 'celebração móvel': formada e transformada continuamente em relação às formas pelas quais somos representados ou interpelados nos sistemas culturais que nos rodeiam. É definida 
historicamente, e não biologicamente. [...] à medida que os sistemas de significação e representação cultural se multiplicam, somos confrontados por uma multiplicidade desconcertante e cambiante de identidades possíveis (HALL, 2006, p. 12-13).

Observa-se com isso, o caráter plural no âmbito das construções identitárias, e que trazendo para um contexto pós-moderno, uma preocupação que esta nova configuração atribuída à sociedade, onde Saracevic (2008) em seus estudos sobre Ciência da Informação vai chamar de "Sociedade da informação", advém com uma característica versada na "liquidez", trazida por Zigmunt Bauman (2001) no seu livro "Modernidade Líquida", onde os indivíduos assumem as identidades que lhe convierem naquele momento, as relações interpessoais são pautadas na instantaneidade, com isso construções e desconstruções sociais são feitas a todo momento e a todo vapor.

A partir dos apontamentos trazidos por Bauman (2001), extrai-se que as relações sociais estão cada dia mais instantâneas e adaptáveis, construções e descontruções são feitas a todo momento no contexto social/cultural e isto reflete em uma preocupação no tocante ao andamento das identidades culturais e como se dará suas perpetuações ao longo do tempo, uma vez que, em relação a primeira, ela "depende, para existir, de algo fora dela: a saber [...], de uma identidade que ela não é [...], mas que, entretanto, fornece as condições para que ela exista [...]. A identidade é, assim, marcada pela diferença" (WOODWARD. 2000, p.09).

Desta forma, a formação do patrimônio e sua posterior preservação surgem como fatores fundamentais neste sentido, pois é a partir do mesmo que se encontra respaldo e reconhecimento acerca de um grupo social, para delimitação de memórias e identidades. "O património expressa a identidade histórica e as vivências de um povo. O Património contribui para manter e preservar a identidade de uma nação daí o conceito de identidade nacional, de um grupo étnico, comunidade religiosa, tribo, clã, família" (CHOAY, 1992, apud Rodrigues, 2012, p.4).

\section{MEMÓRIA SOCIAL}

\section{Le Goff (1998) expõe a memória coletiva como um mecanismo de manipulação que deve ser ora lembrada, ora esquecida, o que nos permite refazer, reforçar ou até mesmo extinguir identidades sociais, dependendo unicamente do interesse de quem detém o poder.}

No contexto da sociedade da informação na atualidade, a memória colocase como uma questão necessária, justamente porque ela representa "fragmentos" que estão relacionados intimamente com identidade social.

A partir do entendimento de Le Goff, compreendemos que memória seria o processo de captar, guardar e recuperar informações que foram fixadas pelo campo cognitivo do ser. Neste entendimento, a memória social seria a socialização de todo este decurso.

Sendo considerado o pioneiro na instituição deste pensamento, o sociólogo Maurice Halbwachs, considerava que memória social se trata do âmago do conhecimento coletivo, conhecido e contextualizado culturalmente entre os indivíduos, e este "conhecimento coletivo", reflete as relações identitárias.

A aproximação observada entre identidade e memória é elucidada por Le Goff (1984, p. 46) "a memória é um elemento essencial do que se costuma chamar identidade, individual ou coletiva, cuja busca é uma das atividades fundamentais dos indivíduos e das sociedades de hoje".

Desta forma, constata-se que a memória é o mecanismo responsável por proporcionar no indivíduo ou grupo, um sentimento de pertencimento, bem como, ressignificar dependendo do contexto dos fatos e acontecimentos do passado. Uma vez que, a memória não configura um processo 
de reconstituição ou resgate, mas sim, uma reconstrução do presente para o passado.

Nesta linha de raciocínio, Gondar (2005) concorda com tal entendimento, alegando que a mesma "não nos conduz a reconstituir o passado, mas sim a reconstruílo com base nas questões que nós fazemos, que fazemos a ele, questões que dizem mais de nós mesmos, de nossa perspectiva presente, que do frescor dos acontecimentos passados", desta forma ela deixa claro como a memória é construída e reconstruída por cada pessoa em cada vez que ela é acionada.

Pollak (1992) também traz uma conceituação acerca de memória social enfatizando seu laço estrito com a identidade, considerando a memória em todas as esferas como um fenômeno construído social e individualmente, e que ao discorrer acerca de memória herdada, constata-se a relação fenomenológica intensa existente entre ela e o sentimento de identidade. Em outras palavras, a relação entre memória e identidade se dá ao passo que esta última se funda como patrimônio de significados, que fazem uma ponte até a criação de uma memória e de um discurso que fundamente a noção de pertencimento.

$$
\text { Partindo para as muitas }
$$

transformações que os contextos social e cultural sofrem, reitera-se a ideia de que as rupturas ocorridas em âmbito social dão margem para a eminência de novas identidades, em face aos choques de perfis. Pomian (1990, p. 62 apud ASSMANN, 2011, p.58), nos traz a seguinte consideração:

A história da construção da herança cultural é definida por uma sequência de rupturas: mudanças de crenças coletivas, modos de vida, reviravoltas tecnológicas, propagação de novos estilos de vida que substituíram estilos antigos. Cada ruptura remove certas classes de artefatos de suas funções e as direcionam para o lixo, para o abandono e para o esquecimento. Assim aconteceu depois da cristianização do império romano, assim depois da invasão dos bárbaros, assim depois de toda revolução industrial e de quase toda a revolução política.

Sendo assim, verifica-se a forte influência e necessidade da informação nesse processo de construção e preservação de identidades e práticas culturais, outrossim pontua-se que a ideia de identidade está imbricada na noção de memória social, esta, por sua vez estabelece uma relação intrínseca com a noção de patrimônio cultural ao passo que desempenha papel fundamental na referenciação da memória de um grupo que sua conjuntura de referenciais e representações alude a uma constituição do que é chamado patrimônio imaterial, pois, conforme Rodrigues (2012, p. 5):

A Antropologia tem demonstrado que todas as sociedades humanas produzem, diferentemente, objetos, ideias, representações simbólicas e comportamentos, que nós, os antropólogos, denominamos cultura. Esse patrimônio cultural, que pode ser material, ou seja, o que é visível, como os artefactos, e não-material, o que não é visível como ideias, comportamentos, sistema simbólico e religioso, é reproduzido e preservado através da memória social.

Desta forma, a memória social irá legitimar a identidade de um determinado grupo, e para tal feitura valer-se-á do patrimônio como instrumento de validação. Todavia compreender quais bens serão considerados patrimônio, reconhecendo limites para esta categoria, são questões necessárias, uma vez que "é possível transitar de uma a outra cultura com a categoria patrimônio, desde que possamos perceber as diversas dimensões semânticas que ela assume e não naturalizemos as nossas representações a seu respeito" (GONÇALVES, 2003, p. 23) e até porque a noção de patrimônio é confundida com a de propriedade o que pode refletir de forma negativa na relação com a memória social. 


\section{CONSIDERAÇÕES FINAIS}

A globalização, de modo especial seus efeitos, são responsáveis pela aproximação das relações interpessoais. Esses efeitos interferiram, bem como continuam interferindo direta e indiretamente nas relações culturais e de identidade, tornando a sociedade multicultural, pluricultural e constantemente diversificando sua dinâmica social.

Identificamos que para determinados grupos sociais suas culturas, tradições, artefatos, monumentos e patrimônios são considerados intrínsecos ao cotidiano. Tais grupos compreendem que em certa medida os fazeres, ações e objetos são resistentes aos avanços da globalização, ao fundamentar a construção social e afirmar a identidade cultural da humanidade.

Os grupos sociais ou indivíduos em sua singularidade buscam através do colecionamento ou acumulação, revestidos de uma intencionalidade, preservar objetos e práticas que referenciam ou até mesmo justificam algum evento histórico ou identidade cultural, guardando em si, a relevância social.
Nesse sentido, o patrimônio não apenas nos faz recordar o passado, mas, prova sua relação intrínseca com a memória, sendo esta responsável pelo processo de reconstrução dos fatos e períodos passados. O patrimônio envolve questões identitárias, que por sua vez está intrinsicamente relacionado com a identidade e consequentemente a memória social do grupo que considera um determinado patrimônio como um bem que lhe pertence.

Entretanto para definirmos os bens passíveis de serem considerados patrimônios e as nuances que envolvem sua delimitação, precisamos primeiramente compreendermos veementemente o que/quem definirá a sua preservação, principalmente, bem como, de maneira inversa, melhor dizendo, para quem esta preservação será direcionada.

A definição de patrimônio e a sua construção é bastante complexa, haja vista envolver uma série de características, fatores e atores neste processo. $O$ patrimônio estabelece com a identidade inúmeras relações, e por tal fato se torna difícil estabelecer conceitos pontuais para cada termo.

\title{
CULTURAL PATRIMONY, IDENTITY AND SOCIAL MEMORY:
}

its interfaces with society

\begin{abstract}
Identity is an important element in understanding the construction and reconstruction of the identities of social groups. However, we can not disregard the relation of cultural heritage with identity and social memory. We intend to highlight social memory as a necessary issue for cultural formations and perpetuation of these, as well as to understand it as an element of representation. Thus, in the discourse of this text we wish to weave the similarities between cultural beritage, identity and social memory through a bibliographical survey on the terms, seeking to foster from this triad the importance of patrimony to the context of identity constructions.
\end{abstract}

Keywords

Cultural Heritage. Identity. Social Memory. Construction. Recognition. Artigo recebido em 27/09/2017 e aceito para publicação em 29/04/2018

\section{REFERÊNCIAS}

ASSMANN, A. Espaços da recordação:

formas e transformações da memória cultural. Tradução: Paulo Soethe. -

Campinas, SP: Editora da Unicamp, 2011.
AZEVEDO NETTO, C. X. Preservação do patrimônio arqueológico: reflexões através do registro e disseminação da informação. Ciência da Informação, v. 37, n. 3, 2008.

BAUMAN, Z. Modernidade líquida. Tradução: Plínio Dentzien. Rio de Janeiro: Jorge Zahar, 2001. 
BRASIL. Constituição Federal de 1988.

Promulgada em 5 de outubro de 1988. Disponível

em:<http://www.planalto.gov.br/ccivil_03/

constituicao/constituição.htm>. Acesso em

07 set. 2017.

CASTELLS, M. O poder da identidade.

São Paulo: Paz e Terra, 2000.

GONÇALVES, J. R S. O patrimônio como categoria de pensamento. In: ABREU, R.; CHAGAS, M. (Orgs.). Memória e patrimônio: ensaios contemporâneos. Rio de Janeiro: Lamparina, p. 21-29, 2003.

Ressonância, materialidade e subjetividade: as culturas como patrimônios. Horizontes antropológicos, v. 11, n. 23, p. 1536, 2005.

GONDAR, J. Quatro proposições sobre memória social. In: GONDAR, J.; DODEBEI, V. O que é memória social. Rio de Janeiro: UNIRIO, 2005.

HALL, S. A identidade cultural na pósmodernidade. Rio de Janeiro: DP\&A editora, 2006.

LE GOFF, J.. Memória. In: : Enci-

clpédia Einaudi: volume 1 - Memoria e História. Imprensa Nacional - Casa da Moeda, 1984.

A história nova. São Paulo:

Martins Fontes, 1998.
MAUSS, M. Ensaio sobre a dádiva. In: Sociologia e antropologia. Rio de

Janeiro: Cosac \& Naify, 2003.

PELEGRINI, S. C. A. Cultura e natureza: os desafios das práticas preservacionistas na esfera do patrimônio cultural e ambiental. Revista Brasileira de História, São Paulo 2006 , v. 26, no 51, p. 115-140.

POLLAK, M. Memória e identidade social. Estudos históricos, Rio de Janeiro, v. 5, n. 10, 1992.

RODRIGUES, D. Patrimônio cultural, memória social e identidade: uma abordagem antropológica. Revista Ubimuseum, v. 1, p. $45-52,2012$.

SALAINI, C. J.; GRAEFF, L. A respeito da materialidade do patrimônio imaterial: o caso do INRC Porongos. Horizontes antropológicos, v. 17, n. 36, p. 171-195, 2011.

SARACEVIC, T. Ciência da informação: origem, evolução e relações. Perspectivas em ciência da informação, v. 1, n. 1, 2008.

SILVEIRA, F. L. A; LIMA FILHO, M. F. Por uma antropologia do objeto documental: entre a "a alma nas coisas" 1 e a coisificação do objeto. Horizontes Antropológicos, v. 11, n. 23, p. 37-50, 2005.

WOODWARD, K. Identidade e diferença: uma introdução teórica e conceitual. In: SILVA, T. T. (ORG.). Identidade e diferença: a perspectiva dos estudos culturais. Petrópolis, RJ: Vozes, 2000. 